\title{
Colonization of Nursing Professionals by Staphylococcus aureus
}

\author{
Josely Pinto de Moura ${ }^{1}$ \\ Fabiana Cristina Pimenta ${ }^{2}$ \\ Miyeko Hayashida ${ }^{3}$ \\ Elaine Drehmer de Almeida Cruz ${ }^{4}$ \\ Silvia Rita Marin da Silva Canini ${ }^{5}$ \\ Elucir Gir ${ }^{6}$
}

This cross-sectional study aimed to investigate the presence of Staphylococcus aureus in the saliva of the nursing team of a teaching hospital in the interior of São Paulo State. Three saliva samples were collected from 351 individuals with an interval of two months between each collection. All ethical aspects were considered. In $867(82.3 \%)$ cultures there was no identification of Staphylococcus aureus in the saliva, in 88 (17.7\%) cultures Staphylococcus aureus was isolated, $26(2.5 \%)$ of which were resistant to methicillin. The prevalence of professionals colonized by Staphylococcus aureus was $41.0 \%$ (144/351), of which $7.1 \%$ (25/351) were characterized as methicillin-resistant Staphylococcus aureus. Transient carriers represented $81.2 \%$ and persistent carriers $18.8 \%$. Resistance to mupirocin was $73.1 \%$ of MRSA and $9.3 \%$ of MSSA. The results demonstrate that it is the nurse and nursing technician that are the professional categories most susceptible to MRSA. Broader discussion on the thematic and interventions are needed.

Descriptors: Staphylococcus aureus; Methicillin Resistance; Nursing, Team; Carrier State; Prevalence.

${ }^{1}$ RN, Doctoral student in Nursing, Escola de Enfermagem de Ribeirão Preto, Universidade de São Paulo, WHO Collaborating Centre for Nursing Research Development, SP, Brazil. E-mail: jpmfonseca@uol.com.br

2 Pharmaceutical, Ph.D. in Sciences, Adjunct Professor, Instituto de Patologia Tropical e Saúde Publica, Universidade Federal de Goiás, Goiânia, GO, Brazil. Centers for Disease Control and Prevention, Atlanta, Estados Unidos. E-mail: pimentaf@hotmail.com.

${ }^{3}$ RN, Ph.D. in Nursing, Escola de Enfermagem de Ribeirão Preto, Universidade de São Paulo, WHO Collaborating Centre for Nursing Research Development, SP, Brazil. E-mail: miyeko@eerp.usp.br.

${ }^{4}$ RN, Ph.D. in Nursing, Adjunct Professor, Departamento de Enfermagem, Universidade Federal do Paraná, PR, Brazil. E-mail: elainedrehmer@yahoo.com.br.

${ }^{5}$ RN, Ph.D. in Nursing, Professor, Escola de Enfermagem de Ribeirão Preto, Universidade de São Paulo, WHO Collaborating Centre for Nursing Research Development, SP, Brazil. E-mail: canini@eerp.usp.br.

${ }^{6}$ RN, Ph.D. in Nursing, Full Professor, Escola de Enfermagem de Ribeirão Preto, Universidade de São Paulo, WHO Collaborating Centre for Nursing Research Development, SP, Brazil. E-mail: egir@eerp.usp.br.

Corresponding Author:

Josely Pinto de Moura

Rua Presidente Antonio Carlos, 36

Bairro: Centro

CEP: 37900-092 Passos, MG, Brasil

E-mail: jpmfonseca@uol.com.br 


\section{A colonização dos profissionais de enfermagem por Staphylococcus aureus}

Este é um estudo transversal e teve como objetivo investigar a presença de Staphylococcus aureus na saliva da equipe de enfermagem de um hospital escola, do interior paulista. Foram coletadas três amostras da saliva de 351 indivíduos, com intervalo de dois meses. Todos os aspectos éticos foram contemplados. Em $867(82,3 \%)$ culturas não houve identificação de Staphylococcus aureus na saliva, em $88(17,7 \%)$ culturas foi isolado Staphylococcus aureus, sendo $26(2,5 \%)$ resistentes à meticilina. A prevalência de profissionais colonizados por Staphylococcus aureus foi de 41,0\% (144/351), dos quais $7,1 \%(25 / 351)$ foram caracterizados como Staphylococcus aureus resistentes à meticilina. Os carreadores transitórios representaram $81,2 \%$ e os persistentes $18,8 \%$. A resistência à mupirocina foi de $73,1 \%$ entre os resistentes à meticilina e $9,3 \%$ nos sensíveis à meticilina. Os resultados evidenciaram que enfermeiras e os técnicos de enfermagem representam as categorias profissionais mais suscetíveis ao MRSA. Discussão mais ampla sobre a temática e intervenções se fazem necessárias.

Descritores: Staphylococcus aureus; Resistência à Meticilina; Equipe de Enfermagem; Portador Sadio; Prevalência.

\section{La colonización de los profesionales de enfermería por Staphylococcus aureus}

Se trata de un estudio transversal que tuvo como objetivo investigar la presencia de Staphylococcus aureus en la saliva del equipo de enfermería de un hospital escuela del interior del estado de Sao Paulo. Fueron recolectadas tres muestras de saliva de 351 individuos con intervalo de dos meses. Todos los aspectos éticos fueron contemplados. En $867(82,3 \%)$ culturas no hubo identificación de Staphylococcus aureus en la saliva, en $88(17,7 \%)$ culturas fue aislado Staphylococcus aureus, siendo $26(2,5 \%)$ resistentes a la meticilina. La prevalencia de profesionales colonizados por Staphylococcus aureus fue de $41,0 \%$ (144/351), de los cuales 7,1\% (25/351) fueron caracterizados como Staphylococcus aureus resistentes a la meticilina. Los portadores transitorios representaron $81,2 \%$ y los persistentes $18,8 \%$. La resistencia a la mupirocina fue de $73,1 \%$ entre los resistentes a la meticilina y $9,3 \%$ en los sensibles a la meticilina. Los resultados evidenciaron que son las enfermeras y los técnicos de enfermería las categorías profesionales más susceptibles al MRSA. Es necesario realizar una discusión más amplia sobre la temática e las intervenciones.

Descriptores: Staphylococcus aureus; Resistencia a la Meticilina; Grupo de Enfermería; Portador Sano; Prevalencia.

\section{Introduction}

The problem regarding health professionals colonized by multiple drug resistant microorganisms is relevant in the world scenario. Among these agents, Staphylococcus aureus (S. aureus) is highlighted, due to it being an important causal pathogen of infections with high incidence of morbimortality ${ }^{(1)}$. The majority of these microorganisms no longer respond to treatment with antimicrobials previously used(2). Multiple drug resistant $S$. aureus is disseminating in the health services, especially those strains resistant to methicillin (MRSA) which leads to greater difficulty in treatment. Although MRSA is typically a hospital agent, there are reports of its dissemination in the community(3).

Infections with $S$. aureus occur more frequently in people colonized with the microorganism, being a long term carrier is the risk factor most strongly associated with subsequent infection ${ }^{(4)}$. From this knowledge, it becomes essential to identify the prevalence in health 
professionals, specifically those who provide direct patient care $^{(5)}$.

In the human populations, approximately $20 \%$ of individuals are carriers of staphylococcus, known as persistent carriers. However, approximately $60 \%$ are considered intermittent carriers and the others never present colonization(6). The anterior nares is considered the primary site of adherence ${ }^{(1,6)}$, however, there are reports of observations of high rates of MRSA in the throat in children ${ }^{(7)}$. A recent study showed that, contrary to expectations, colonization is more persistent in the throat than in the anterior nares ${ }^{(8)}$. Although the studies chose the nasal vestibule as the site of choice for the investigation of MRSA carriers, there is evidence that the oral cavity is also a reservoir, which makes the dispersion of droplets produced by talking, coughing and sneezing relevant ${ }^{(9)}$. The transmission of MRSA from professionals to family members has been documented $^{(10)}$ and, in Brazil, research conducted at a university hospital showed that the incidence of nasal colonization among nursing professionals in critical care units was $38.23 \%(52 / 136)^{(11)}$.

A study on the clinical significance of MRSA infections indicated that this microorganism has been responsible for the greatest panorama of hospital infection that the world has experienced(12). The length of time spent in the hospital, contact with patients, and lack of adherence to standard precautionary measures causes health professionals to be subject to colonization by microorganisms that are typically hospital agents and often multiresistant, placing them in the condition of carriers and disseminators, contributing to the occurrence of outbreaks of infection. Thus, research becomes urgent in the health area, particularly for nursing, aiming to ensure a positive impact in the care, with a view to improving its quality both for clients and the health community in general.

In order to analyze the magnitude of the problem presented, this study was conducted with the aim of identifying the presence of $\mathrm{S}$. aureus, and the respective antimicrobial susceptibility, in the saliva of nursing professionals of a public hospital.

\section{Methods}

This was a cross-sectional epidemiological study conducted from January to December 2007, in the intensive care (ICU), internal medicine, clinical surgical, and gynecological-obstetric units of a large teaching hospital in the interior of São Paulo State. The project was approved by the Research Ethics Committee of the Hospital under study, protocol No. 9918/2005. The collection of data and samples of saliva was performed after obtaining the signature of the terms of free prior informed consent from the participant. Study participants were nurses, technicians and auxiliary nurses in professional activities at the time of data collection, who agreed to participate. Three samples of saliva were obtained from 351 subjects with an interval of two months between collections; the professionals who did not provide a total of three samples were excluded from the study. The chosen demographic and professional variables of the participants were: gender, age, professional category, shift, length of working week and length of time working in the institution, existence of a second employment contract, unit of work, as well as the prevalence and classification of the colonization, whether sensitive or resistant to methicillin, and the phenotypic characterization of S. aureus.

The laboratory processing consisted of homogenization of the saliva for one minute, ten-fold dilution in saline solution $(0.8 \%)$ and inoculation ${ }^{(13)}$ into Petri dishes containing the selective culture medium, mannitol salt agar. The colonies typical of $S$. aureus were phenotype tested using: Gram stain, coagulase, catalase, mannitol fermentation, DNase and lecithinase for the differentiation and identification of the genus and species. The antimicrobial susceptibility tests were performed using the disk diffusion method and followed the recommendations of the Clinical and Laboratory Standards Institute (CLSI) $)^{(14)}$. The data were processed and analyzed through descriptive statistics using the public domain software EPI-Info version 3.5.1.

\section{Results}

A total of 351 nursing professionals participated in the research, being 305 ( $86.9 \%$ ) female, aged between 21 and 64 years (mean 40.3 \pm 9.2 ), and focused in the age group 30 to 49 years $(65.3 \%)$. The total included $233(66.4 \%)$ auxiliary nurses, 38 (10.8\%) nursing technicians and $80(22.8 \%)$ nurses, who worked on a rotation basis $(37.3 \%)$, in the morning $(20.8 \%)$ in the afternoon (17.1\%) and at night (24.8\%), with a working week of $30(83.2 \%)$ or more than $30(16.8 \%)$ hours. Length of time working in the institution ranged from

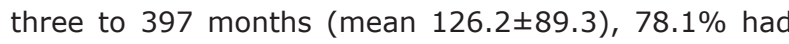
an employment contract only with the institution under study, $5.7 \%$ with another institution as well and $16.2 \%$ provided no information. The professionals constitute 
part of the functional framework of the hospitalization unit in the specialties: medical (37.3\%), surgical $(30.2 \%)$, intensive care $(16.0 \%)$, gynecology and obstetrics $(16.5 \%)$.

Three saliva samples were collected from 351 participants, totaling 1053 samples, which resulted in 207 (59\%) professionals not colonized by S. aureus, the others had at least one positive culture and were considered colonized by S. aureus in the saliva (41\%). Among those colonized, 104 (29.6\%) were considered carriers of methicillin-sensitive $S$. aureus (MSSA) and $25(7.1 \%)$ methicillin-resistant S. aureus (MRSA), 15 $(4.3 \%)$ cultures were not recovered for the completion of the antibiogram and were considered as undefined regarding sensitivity to antimicrobials.

The characterization of the subjects classified as colonized or not by MSSA or MRSA, according to the variables gender, age, shift and working week, is presented in Table 1.

Table 1 - Demographic Characteristics, shift and working week of the employees of a State public hospital regarding the colonization by methicillin-sensitive Staphylococcus aureus (MSSA) and methicillin-resistant Staphylococcus aureus (MRSA), Ribeirão Preto, Brazil, 2007

\begin{tabular}{|c|c|c|c|c|c|c|c|c|c|c|}
\hline \multirow{3}{*}{ Variables } & \multirow{2}{*}{\multicolumn{2}{|c|}{$\begin{array}{l}\text { Not Colonized } \\
\quad(n=207)\end{array}$}} & \multicolumn{6}{|c|}{ Colonized $(n=144)$} & \multirow{2}{*}{\multicolumn{2}{|c|}{ Total }} \\
\hline & & & \multicolumn{2}{|c|}{ MSSA (n=104) } & \multicolumn{2}{|c|}{ MRSA $(n=25)$} & \multicolumn{2}{|c|}{ Ignored* $(n=15)$} & & \\
\hline & f & $\%$ & $f$ & $\%$ & f & $\%$ & f & $\%$ & $f$ & $\%$ \\
\hline \multicolumn{11}{|l|}{ Gender } \\
\hline Female & 183 & 60.0 & 85 & 27.9 & 23 & 7.5 & 14 & 4.6 & 305 & 100 \\
\hline Male & 24 & 52.2 & 19 & 41.3 & 02 & 4.3 & 01 & 2.2 & 46 & 100 \\
\hline \multicolumn{11}{|l|}{ Age (years) } \\
\hline 21 to 29 & 22 & 42.3 & 25 & 48.1 & 5 & 9.6 & 0 & 0.0 & 52 & 100 \\
\hline 30 to 39 & 64 & 55.2 & 30 & 25.8 & 11 & 9.5 & 11 & 9.5 & 116 & 100 \\
\hline 40 to 49 & 79 & 69.9 & 30 & 26.5 & 2 & 1.8 & 2 & 1.8 & 113 & 100 \\
\hline$\geq 50$ & 42 & 60.0 & 19 & 27.1 & 7 & 10.0 & 2 & 2.9 & 70 & 100 \\
\hline \multicolumn{11}{|l|}{ Work shift } \\
\hline Rotation & 75 & 57.2 & 38 & 29.0 & 12 & 9.2 & 06 & 4.6 & 131 & 100 \\
\hline Morning & 44 & 60.3 & 25 & 34.3 & 02 & 2.7 & 02 & 2.7 & 73 & 100 \\
\hline Afternoon & 35 & 58.3 & 19 & 31.7 & 06 & 10.0 & - & - & 60 & 100 \\
\hline Night & 53 & 60.9 & 22 & 25.3 & 05 & 5.7 & 07 & 8.1 & 87 & 100 \\
\hline \multicolumn{11}{|l|}{ Working week (hours) } \\
\hline 30 & 173 & 59.3 & 83 & 28.4 & 22 & 7.5 & 14 & 4.8 & 292 & 100 \\
\hline$>30$ & 34 & 57.6 & 21 & 35.6 & 03 & 5.1 & 01 & 1.7 & 59 & 100 \\
\hline
\end{tabular}

* Not recovered

In relation to the colonized professionals, the majority were female, however, the incidence of males was higher among the MSSA carriers. Regarding age, it was found that the non-colonized professionals were predominantly in the age group 40 to 49 years (69.9\%); the MSSA carriers predominantly in the age group 21 to 29 years $(48.1 \%)$, and among the MRSA carriers, the proportions in each age group were similar, with the exception of the age group 40 to 49 years that had fewer. The rotation was found to be the shift of higher frequency of subjects in all categories. In relation to the professional category the auxiliary nurses and the nursing technicians presented a higher incidence of Staphylococcus aureus carriers, however, among MRSA carriers there was a prevalence of nurses and nursing technicians, with a greatly reduced number of auxiliary nurses. There was little significance regarding the presence or absence of colonization among workers who reported working in one or in more than one institution.

Analyzing the conditions of colonization, stratified by work unit, it was found that the sectors with the highest percentage of non-colonized workers were the obstetrics center (73.7\%) and the gynecology and obstetrics clinic $(71.8 \%)$. The sectors which had the higher prevalence of professionals colonized by MSSA were: the metabolic unit $(50 \%)$, the bone marrow transplantation center $(44.4 \%)$ and the internal medicine units of the fifth $(42.5 \%)$ and sixth (42.9\%) floors. The sectors with the highest number of MRSA carriers were the neurological intensive care unit $(14.3 \%)$, the internal medicine unit $(14.2 \%)$ and clinical surgical unit $(14.0 \%)$. Carriers of MRSA were also identified in the metabolic (12.5\%) and 
hematology units $(10 \%)$. It is noteworthy that in the obstetrics center and in the bone marrow transplantation unit, no MRSA carriers were identified.

After detection of S. aureus in $17.6 \%(186 / 1053)$ of the samples, these were submitted to antibiogram testing to verify their antimicrobial susceptibility. From this 26 MRSA were identified, and the others were characterized as MSSA. Antibiogram testing was not performed for $15 \mathrm{~S}$. aureus isolates, because it was not possible to recover samples. Regarding the profile of antimicrobial susceptibility among the MRSA isolates, $96.1 \%$ were resistant to penicillin, $76.9 \%$ to cefotaxime and clindamycin and $73.1 \%$ to mupirocin. Therefore, besides the resistance to penicillins and cephalosporins, the results also showed resistance to other classes, i.e. to lincosamides (clindamycin) and mupirocin (Table 2).

Table 2 - Percentage of methicillin-resistant S. aureus (MRSA) and methicillin-sensitive S. aureus (MSSA) with antimicrobial resistance, isolated from saliva samples of health workers of a State public hospital, Ribeirão Preto, Brazil, 2007

\begin{tabular}{|c|c|c|c|c|c|c|c|c|}
\hline S. aureus & Oxacilin & Penicilin & Cefotaxime & Erythromycin & Clindamycin & \multicolumn{2}{|c|}{ Tetracycline } & Rifampicin \\
\hline MRSA $(n=26)$ & 100.0 & 96.1 & 76.9 & 46.1 & 73.1 & \multicolumn{2}{|c|}{42.3} & 50.0 \\
\hline MSSA $(n=142)$ & 0.0 & 72.5 & 9.1 & 26.0 & 12.0 & \multicolumn{2}{|c|}{7.0} & 9.8 \\
\hline S. aureus & Ciprofloxacin & Ger & icin & nethoxazole $+\mathrm{Tr}$ & thoprim & mycin & Linezolid & Mupirocin \\
\hline MRSA $(n=26)$ & 3.8 & & & 15.4 & & 0 & 3,8 & 73,1 \\
\hline $\operatorname{MSSA}(n=142)$ & 2.1 & & & 2.8 & & 0 & 7,7 & 9,8 \\
\hline
\end{tabular}

The profile of antimicrobial susceptibility relative to MSSA, presenting high resistance to penicillin (72.1\%) and low resistance to the other antimicrobials tested, was completely different to that of MRSA.

\section{Discussion}

Of the total 1,053 samples, the positivity was $17.6 \%(186 / 1053)$ for the isolated etiologic agent $S$. aureus and $2.5 \%(26 / 1053)$ for MRSA, considering all samples. However, when analyzing the prevalence per subject, a $41.0 \%$ (144/351) prevalence of $S$. aureus was found, being $7.1 \%$ (25/351) of MRSA and $29.6 \%(104 / 351)$ of MSSA. In studies carried out with methodology and hospital characteristics similar to the present study, which assessed the prevalence of $S$. aureus in health professionals, the highest prevalence of $S$. aureus was obtained in Goiânia $(84.7 \%)^{(14)}$. Regarding the prevalence of MRSA, the highest was found in Curitiba $(12.7 \%)^{(9)}$ and the lowest was found in Santo André $(4.1 \%)^{(15)}$. The results encountered in the present study, when compared to the others, proved to be of an intermediate value, i.e. the MRSA colonization rate was $7.1 \%$. In the hospital in Curitiba, the rate of colonization by $S$. aureus was lower when compared to Goiania. Among the 486 professionals studied, 296 (60.9\%) were considered colonized and 190 (39.1\%) were classified as non-carriers of $S$. aureus. In the study in Santo André(15) the prevalence of colonization by $S$. aureus obtained was $47.6 \%$. Although there is a diversity of published results, a systematic review published in $2008^{(16)}$ showed a mean of $4.5 \%$ of MRSA colonization in health workers. Therefore, the index obtained in this study $(7.1 \%)$ was considered elevated, although low when compared to other similar studies $12.7 \%{ }^{(9)}$ and $12 \%{ }^{(17)}$. A study conducted over twenty years ago in the same institution of the present study, among nursing professionals from various sectors, investigated the colonization in different anatomical sites (nasal cavity, oropharynx and hands) and found the prevalence of carriers of $S$. aureus in one or more of the anatomical sites studied to be $40.6 \%{ }^{(18)}$. Knowledge of the carrier status and decolonization reduce the risk of subsequent infections. Some authors ${ }^{(9,16)}$ consider the possibility of inserting the condition of MRSA colonization or infection as an occupational event backed by the labor law.

Regarding the prevalence of workers colonized with MSSA, according to the areas of performance, the highest rate was among the carriers of the metabolic unit, the bone marrow transplantation unit and the internal medicine units, however, the sites with the highest prevalence of MRSA were the neurological ICU, the internal medicine unit and the clinical surgical unit. A fact that deserves to be emphasized is that the neurological ICU patients are usually coming from the clinical surgical unit and the sectors are contiguous, the patients discharged from the neurological ICU, in most cases, are referred to the clinical surgical unit. In other sectors MRSA carriers were also identified in smaller proportions, which highlights some sectors of greater susceptibility of the clients, where the presence of a single carrier of MRSA can be a major risk factor for the clients. These sectors are the metabolic, hematology 
and liver transplantation units. In these locations, the decolonization of colonized professionals is considered relevant as well as performing surveillance cultures of the team. One study ${ }^{(19)}$ found that among ICU patients, MRSA colonization was associated with subsequent infection and risk of death. Active surveillance for MRSA colonization may identify individuals at risk of these adverse outcomes and improve the prevention programs.

A higher incidence of colonization in the ICU and in the clinic of infectious diseases was expected, however, the opposite was the case. One hypothesis for this fact is that when workers are aware of the carrier condition of their patients, they take more care when handling them, i.e. the perception of risk of contamination leads to workers better protecting themselves.

Regarding the profile of antimicrobial susceptibility of MRSA there is a situation of limited treatment options for carriers of infection. Another aggravating aspect found was resistance to mupirocin, which is considered the antibiotic of choice for decolonization of MRSA carriers. In relation to MSSA carriers, the situation appears to be much less worrisome because this microorganism presents sensitivity to various antimicrobials. Concerning the resistance to methicillin, the decolonization of mucosae and skin should be considered. The topical antimicrobial mupirocin is recommended for the decolonization of the nasal mucosa and of cutaneous lesions of patients or health professionals ${ }^{(5,20)}$. This measure aims to limit the spread of this agent in the health services, and thereby to reduce the great clinical impact produced by it in hospital infections, especially those related to surgical procedures and vascular catheters ${ }^{(20)}$. However, the resistance to mupirocin presented in the hospital of this study, which affected $9.3 \%$ of the MSSA carriers, cannot be compared to a standard due to its variability.

For the strategy of decolonization of carries to be effective, its use should be properly evaluated, considering the need for reflection on the routine use of mupirocin and the probability of resistance development associated with the usage policy(21). The results of this study highlight the problem of multidrug resistance and the need for a critical evaluation of the use of antimicrobials, even topical ones, in the quotidian practice. In one study ${ }^{(16)}$, the authors invite reflection on this question: Are health workers the source, transmitters or victims of MRSA? These roles are not exclusive, therefore difficult to differentiate. However, policies of investigation of the carrier status of workers in outbreak situations are justified. This approach is also made necessary for the occupational protection of workers and to prevent the spread of multiresistant bacteria in the hospital environment and consequently to prevent a worldwide public health problem.

\section{Conclusions}

Among the 1053 saliva cultures of the workers of a public hospital $186(17.6 \%)$ were positive. A prevalence of $41.0 \%$ of health workers colonized by $S$. aureus was encountered, of which $29.6 \%$ were colonized by MSSA, $7.1 \%$ by MRSA and $4.3 \%$ were without antibiogram. Resistance to mupirocin was observed among the MRSA carriers (73.1\%) and among MSSA carriers (9.3\%), configuring a relevant result due to this interfering in the preventive measures currently recommended for specific situations.

The results demonstrate that it is the nurse and nursing technician that are the professional categories most susceptible to MRSA. The length of time working at the institution did not have a strong correlation with the colonization of the professional, because workers with less time at the institution also had a high incidence of colonization. One risk situation identified was the presence of MRSA carriers in sectors with greater susceptibility of their clientele and consequently the configuration of a situation of greater gravity. The sectors mentioned are the metabolic unit, ICU, liver transplant unit, hematology unit, and clinical gynecology and obstetrics unit.

This situation represents a risk to the patient and the worker, and requires specific studies and interventions for the prevention and control of MRSA, especially considering the condition of special sectors. Public policies need to reinforce the specific programs of antimicrobial resistance, with national campaigns addressing this thematic, because only systematic and controlled actions can support the challenge of the spread of resistant bacteria.

\section{References}

1. Lowy F D. Staphylococcus aureus infections. N Engl J Med. 1998;339(8):520-32.

2. Center for Disease Control and Prevention (CDC). Siegel JD, Rhinehart E, Jackson M, Chiarello L. Healthcare Infection Control Practices Advisory Committee (HICPAC). Management of Multidrug-Resistant Organisms in Healthcare Settings. Atlanta (GA): Centers for Disease Control and Prevention; 2006. 74 p.

3. Center for Disease Control and Prevention (CDC). Four pediatric deaths from community-acquired methicillin- 
resistant Staphylococcus aureus Minesota and North Dakota, 1997-1999. JAMA. 1999;282(12):123-5.

4. Kuehnert MJ, Kruszon Moran D, Hill HA, McQuillan G, McAllister SK, Fosheim G, et al. Prevalence of Staphylococcus aureus nasal colonization in the United States, 2001-2002. J Infect Dis. 2006;193(2):172-9.

5. Coia JE, Duckworth GJ, Edwards DI, Farrington M, Fry $C$, Humphreys $H$, Mallaghan $C$, Tucker DR, et al. For the joint working party of the British Society of Antimicrobial chemotherapy, the Hospital Infection Society, and the Infection Control Nurses Association Guidelines for the control and prevention of meticilinresistant Staphylococcus aureus (MRSA) in healthcare facilities. J Hosp Infect. 2006;63:S1-44.

6. Kluytmans A, Belkun A, Verbrugh HN. Carriage of Staphylococcus aureus: epidemiology, underlying mechanisms and associated risks. Clin Microbiol Rev. 1997;10(3):505-20.

7. Hayakawa T, Hayashidera T, Yoneda K, Kagawa S, Kusunoki T. Preferential pharyngeal colonization of methicillin resistant Staphylococcus aureus in infants [letter]. J Pediatr. 1999;134(2):252.

8. Nilsson P, Ripa T. A colonização da garganta por Staphylococcus aureus é mais frequente que a colonização na narina anterior. J Clin Microbiol. 2006;44(9):3334-9.

9. Cruz EDA. Staphylococcus aureus e Staphylococcus resistente à meticilina em trabalhadores de um hospital universitário: colonização e crenças em saúde. [Tese Doutorado]. Ribeirão Preto (SP): Escola de Enfermagem de Ribeirão Preto da Universidade de São Paulo; 2008.189 p.

10. Eveillard $M$, Martin $Y$, Hidri $N$, Boussougant $Y$, Joly Guillou ML, Carriage of methicillin -resistant Staphylococcus aureus among hospital employees: prevalence, duration, and transmission to households. Infect Control Hosp Epidemiol. 2004;25(2):114-20.

11. Weiss RDN, Fagundes CB. Mezzomo N. Prevalência e suscetibilidade de "Staphylococcus aureus" colonizadores de fossas nasais da equipe de enfermagem do Hospital Universitário de Santa Maria, RS. Congresso Brasileiro de Controle de Infecção e Epidemiologia Hospitalar, 2002. Curitiba: ABIH; 2002. 246 p.

12. Gould IM. The clinical significance of methicillinresistant Staphylococcus aureus. J Hosp Infect. 2005;61(4):277-82.

13. Westergren G, Krasse B. Evaluation of a micromethod for determination Streptococcus mutans and Lactobacillus infection. J Clin Microbiol. 1978;7(1):82-3.

14. Clinical and Laboratory Standards Institute (CLSI). Approved Standards M2-A8. Performance Standards for
Antimicrobial Disk Susceptibility Tests. 8.ed. Approved Standard. Wayne (PA): NCCLS; 2005.

15. Carvalho MJ, Pimenta FC, Hayashida M, Gir E, Barbosa $\mathrm{CP}$, Canini SRMS, et al. Prevalence of methicillin-resistant and methicillin-susceptible $S$. aureus in the saliva of health professionals. Clinics. 2009;64(4):295-305.

16. Albrich WC, Harbarth S. Health-care worker: source, vector, or victim of MRSA? Lancet Infect Dis. 2008;8(5):289-301.

17. Ibarra M, Flatt T, Van Maele D, Ahmed A, Fergie J, Purcell K. Prevalence of methicillin-resistant Staphylococcus aureus nasal carriage in healthcare workers. Pediatr Infect Dis J. 2008;27(12):1109-11.

18. Santos BMO. Prevalência de portadores säos de Staphylococus aureus em pessoal de diferentes categorias de enfermagem de um hospital geral escola. Rev. Latino-Am. Enfermagem. 2000;8(1):67-73.

19. Patel M, Weinheimer JD, Waites KB, Baddley JW. Active surveillance to determine the impact of methicillinresistant Staphylococcus aureus colonization on patients in intensive care units of a Veterans Affairs Medical Center. Infect Control Hosp Epidemiol. 2008;29(6):503-9.

20. Wertheim H F, Vos MC. Can mupirocin prevent methicillin-resistant Staphylococcus aureus infections? Crit Care. 2005;9(3):257-8.

21. Netto dos Santos KR, Fonseca LS, Gontijo PP Filho. Emergence of high-level mupirocin resistance in methicillin-resistant Staphylococcus aureus isolated from Brazilian university hospitals. Infect Control Hosp Epidemiol. 1996;17(12):813-6. 